\title{
THE EFFECT OF COMPOSITION, MISFIT, AND HEAT TREATMENT ON THE PRIMARY CREEP BEHAVIOR OF SINGLE CRYSTAL NICKEL BASE SUPERALLOYS PWA 1480 AND PWA 1484
}

\author{
B.C. Wilson ${ }^{1}$ and G.E. Fuchs ${ }^{1}$ \\ ${ }^{1}$ University of Florida; P.O. Box 116400; Gainesville, FL 32611, USA
}

Keywords: Creep, Misfit, Heat Treatment, Rhenium, Gamma Prime, XRD

\begin{abstract}
Primary creep occurring at intermediate temperatures $\left(650^{\circ} \mathrm{C}\right.$ to $850^{\circ} \mathrm{C}$ ) and loads greater than $500 \mathrm{MPa}$ has been shown to result in significant primary creep strain (often exceeding 5-10\%) during the first few hours of a creep test. This investigation examines how rhenium additions and aging heat treatment affect the primary creep behavior of PWA 1480 and PWA 1484. To aid in the understanding of rhenium's role in primary creep, $3 \mathrm{wt} \% \mathrm{Re}$ was added to PWA 1480 to create a second generation version of PWA 1480. The aging heat treatments used for creep testing were either $704^{\circ} \mathrm{C} / 24 \mathrm{hr}$. or $871^{\circ} \mathrm{C} / 32 \mathrm{hr}$. For all test temperatures, the high temperature age resulted in a significant decrease in primary creep behavior of PWA 1484 and a longer lifetime for all but the lowest test temperature. The primary creep behavior of PWA 1480 and PWA $1480+$ Re did not display any significant dependence on age heat treatment. The creep rupture life of PWA 1480 is greater than PWA 1484 at $704^{\circ} \mathrm{C}$, but significantly shorter at $760^{\circ} \mathrm{C}$ and $815^{\circ} \mathrm{C}$. PWA $1480+\mathrm{Re}$, however, displayed the longest lifetime of all three alloys at both $704^{\circ} \mathrm{C}$ and $815^{\circ} \mathrm{C}$ (PWA $1480+\mathrm{Re}$ was not tested at $760^{\circ} \mathrm{C}$ ). X-ray diffraction and TEM analysis offer insight into the possible causes in the difference in behavior. PWA 1480 was found to deform by dislocations constrained to the $\gamma$ matrix while PWA 1484 is dominated by stacking fault shear of the $\gamma^{\prime}$ phase. The modified PWA $1480+\mathrm{Re}$ contained stacking fault shear from more than one slip system and displayed the least amount of primary creep. Only after sufficient dislocation debris builds at the $\gamma / \gamma^{\prime}$ interfaces, does secondary creep start.
\end{abstract}

\section{Introduction}

The primary creep behavior of single crystal, nickel-base superalloys has experienced a resurgence of research interest over the past several years. As the high temperature creep behavior of these alloys has been improved dramatically through strict alloy chemistry control utilizing refractory elements like rhenium, Re, an interesting behavior developed in some second generation superalloys during creep at intermediate temperatures $\left(650^{\circ} \mathrm{C}\right.$ $850^{\circ} \mathrm{C}$ ) and high loads (greater than $500 \mathrm{MPa}$ ) [1-4]. Under these conditions some second generation alloys, like PWA 1484 and CMSX-4, have been shown to exhibit non-uniform deformation producing large primary creep strains in only a few hours [4-6]. After this initial surge in elongation, the creep rate drops by as much as 2 orders of magnitude during the onset of secondary or steady-state creep.

Primary creep has been tied to numerous causes. Among the most common are specimen orientation $[1,2,4]$, the presence of secondary $\gamma^{\prime}[4,7]$, lattice misfit $[8,9]$, and alloy composition [4]. Mechanistically, large primary creep strains have been linked to cooperative shearing of $\gamma^{\prime}$ precipitates by $\mathrm{a}<112>$ dislocation ribbons [2]. These dislocation ribbons are thought to originate from $\mathrm{a} / 2<011>$ dislocations in the $\gamma$ matrix. If the resolved stress is high enough, 2 matrix dislocations can then enter a $\gamma^{\prime}$ precipitate by the formation of $2<112>$ type dislocations with a stacking fault in between. As the dislocation pair moves through the precipitate, it leaves behind an anti-phase boundary, APB, due to the ordered nature of the $\gamma^{\prime}$. As a result, a second set of dislocations must follow to eliminate the APB. Several discussions of this mechanism can be found in (Rae et al., 2001) [1], (Link and Feller-Kniepmeier, 1990) [9], (Caron, et al., 1988) [10], and (Knowles and Chen, 2003) [11]. While the common deformation mechanisms linked to primary creep have been identified, the factors that determine whether it happens in a given alloy are still not entirely clear.

Orientation sensitivity has been shown to significantly impact primary creep. This is expected as primary creep has been linked to slip on a limited numbers of slip systems. With fewer slip systems activated these orientations will experience less workhardening and, subsequently, more primary creep. Conversely, if the sample is oriented in a manner that allows multiple slip systems to operate, creating greater work-hardening potential, then primary creep likely would not be as significant due to dislocation interactions and the buildup of dislocation networks along the $\gamma / \gamma^{\prime}$ interfaces. These processes, in effect, limit deformation to the $\gamma$ matrix [2]. In fact, it has been reported through the use of modeling predictions that creep deformation limited to the $\gamma$ matrix channels can only account for about $0.3-$ $0.5 \%$ primary creep deformation. Research into shear band formation in single crystal superalloys, however, has shown that there are factors, besides orientation, involved in shear band formation. For instance, the presence of secondary $\gamma^{\prime}$ in the $\gamma$ matrix channels may enhance shear band formation [7]. Other significant indicators of $\gamma^{\prime}$ shear may be lattice misfit and precipitate coherency between the $\gamma$ matrix and the $\gamma^{\prime}$ precipitates $[8,9]$.

Secondary $\gamma^{\prime}$ precipitates are typically about $10-50 \mathrm{~nm}$ in size within $\gamma$ channels roughly $50-150 \mathrm{~nm}$ in width. These precipitates form during cooling from the last age heat treatment that is applied to an alloy. An alloy can be made to have no secondary precipitates if cooled very slowly from this last step [7]. The presence of these precipitates has been linked to large primary creep strains when compared to the same alloy without secondary precipitates. One reason may be that these particles add resistance to the normal dislocation bowing mechanism that would tend to fill the $\gamma$ channels with dislocations and create large networks of interfacial dislocations. This resistance to normal dislocation glide processes may add "pressure" to dislocations at the $\gamma / \gamma$ " interface that enables the dislocations to overcome the energy barrier preventing their entry into the ordered precipitates. As these dislocations enter, dissociate, and form shear bands, the mean free path for their glide in the $\gamma^{\prime}$ phase is much greater than in the $\gamma$ matrix. Consequently, primary creep is enhanced [7]. 
Increasing the free-glide distance will increase primary creep strains while avoiding adequate work-hardening to force the onset of secondary creep. By the time secondary creep is reached, significant creep deformation has already occurred [2].

Lattice misfit and precipitate coherency at the $\gamma / \gamma^{\prime}$ interface may also control whether dislocations can enter the $\gamma^{\prime}$ phase and form shear bands. Alloys with relatively large negative lattice misfits ($0.2 \%$ to $-0.5 \%$ ) create dense interfacial networks of dislocations. As these networks form, matrix dislocations are drawn to the $\gamma / \gamma$ ' interface to relieve the misfit stress. Alloys with large misfit values tend to have superior creep properties as deformation is more often limited to the $\gamma$ matrix $[12,13]$. As more dislocations settle at the interface, the mesh spacing gets smaller and will further prevent dislocations from entering and shearing the primary $\gamma^{\prime}$ precipitates. Alloys with lattice misfit values close to zero tend to form networks with larger mesh sizes during creep resulting in inferior creep properties. This behavior has also been correlated with creep data [8, 9, 12-15]. It would be expected then that alloys with larger (more negative) misfit would be more resistant to stacking fault shear and primary creep.

Finally, alloy composition has a significant impact on the propensity for primary creep. This would be expected as this behavior is primarily seen in second generation alloys and because alloy composition impacts many different properties. Lattice misfit, stacking fault energy, and anti-phase boundary energy can all be impacted by various elemental additions. Rhenium, in particular, may also be linked to primary creep because of the number of second generation alloys that display this behavior despite accounts of $\mathrm{Re}$ segregating almost exclusively to the $\gamma$ phase $[16,17]$. In alloys containing tungsten, however, as much as $20 \%$ of the Re added to the alloy has been shown to partition to the $\gamma^{\prime}$ [18]. Varying composition can have significant effects on mechanical properties due to these fine-scale changes.

This investigation focuses on the effect of rhenium, age heat treatment, and the resulting lattice misfit of single crystal, nickel- base superalloys PWA 1480 and PWA 1484. A third alloy, named PWA $1480+$ for the purposes of this research, was created by adding $3 w t . \%$ Re to a master heat of PWA 1480 . Utilizing creep testing, X-ray diffraction (XRD), and transmission electron microscopy (TEM) techniques, the primary creep behavior was observed for all three alloys with two different age heat treatments. The goal of this research is to aid in the understanding of the factors that allow or resist primary creep in modern single crystal superalloys.

\section{Experimental Procedure}

\section{$\underline{\text { Material }}$}

This investigation utilized three alloys, PWA 1480, PWA 1480+, and PWA 1484, with the compositions given in Table I. All three alloys were cast into single crystal bars by Pratt \& Whitney Aircraft Engines (East Hartford, CT) using a modified Bridgman technique for a total of 47 bars (17 of PWA 1480, 12 of PWA $1480+$, and 18 of PWA 1484. Each bar measured $1.6 \mathrm{~cm}$ in diameter by $18 \mathrm{~cm}$. long and was used to produce $2 \mathrm{creep} /$ tensile specimens. Bars with orientations within $5^{\circ}$ of the [001] casting direction were selected for mechanical testing to greatly reduce the effect of orientation on the results. These bars were then given a custom solution heat treatment to reduce the effects of $\gamma / \gamma^{\prime}$ eutectics and coring due to solidification. The bars were then divided into two groups to receive one of two different age heat treatments: $704^{\circ} \mathrm{C} / 24 \mathrm{hr}$. $/$ air cool or $871^{\circ} \mathrm{C} / 32 \mathrm{hr}$. $/$ air cool. These age heat treatments were selected because they have been shown to have an impact on creep behavior in these alloys. Additionally, it should be noted that creep testing was conducted at temperatures below the $871^{\circ} \mathrm{C}$ age, but at equal or greater temperatures than the $704^{\circ} \mathrm{C}$ age. The full heat treatment schedule is given in Table II. Metallography was performed on samples polished in the usual way with the application of two different etchants. The first was a $\gamma^{\prime}$ etch and the second was an electrolytic $\gamma$ etch.

Table I. Compositions in wt.\% of the alloys used in this study.

\begin{tabular}{|lllllllllllll|}
\hline Alloy & Generation & $\mathrm{Co}$ & $\mathrm{Cr}$ & $\mathrm{Mo}$ & $\mathrm{W}$ & $\mathrm{Ta}$ & $\mathrm{Re}$ & $\mathrm{Al}$ & $\mathrm{Ti}$ & $\mathrm{Hf}$ & $\mathrm{C}$ & $\mathrm{Ni}$ \\
\hline PWA 1480 & 1st & 5 & 10 & - & 4 & 12 & - & 5 & 1.5 & - & 0.04 & Bal. \\
PWA 1480+ & 2nd & 5 & 10 & - & 4 & 12 & 3 & 5 & 1.5 & - & 0.04 & Bal. \\
PWA 1484 & 2nd & 10 & 5 & 2 & 6 & 9 & 3 & 5.6 & - & 0.1 & 0.02 & Bal. \\
\hline
\end{tabular}

Table II. Heat treatment schedule for all three alloys. All samples were given a solution heat treatment, a coating heat treatment, and either the LT age or the HT age.

\begin{tabular}{|c|c|c|c|c|c|}
\hline Alloy & \multicolumn{2}{|c|}{ Solution Heat Treatment } & Coating Cycle & LT Age & HT Age \\
\hline PWA 1480 & HT3 & $1295^{\circ} \mathrm{C} / 1 \mathrm{hr} . \rightarrow 1299^{\circ} \mathrm{C} / 1 \mathrm{hr} . \rightarrow 1302^{\circ} \mathrm{C} / 10 \mathrm{hr} . / \mathrm{GFQ}$ & $1080^{\circ} \mathrm{C} / 4 \mathrm{hr} . / \mathrm{GFQ}$ & $704^{\circ} \mathrm{C} / 24 \mathrm{hr} . / \mathrm{AC}$ & $871^{\circ} \mathrm{C} / 32 \mathrm{hr} . / \mathrm{AC}$ \\
\hline PWA $1480+$ & HT3 & $\begin{array}{l}1293^{\circ} \mathrm{C} / 1 \mathrm{hr} . \rightarrow 1296^{\circ} \mathrm{C} / 1 \mathrm{hr} . \rightarrow 1299^{\circ} \mathrm{C} / 2 \mathrm{hr} . \\
\rightarrow 1302^{\circ} \mathrm{C} / 1 \mathrm{hr} . \rightarrow 1308^{\circ} \mathrm{C} / 4 \mathrm{hr} . / \mathrm{GFQ}\end{array}$ & $1080^{\circ} \mathrm{C} / 4 \mathrm{hr} . / \mathrm{GFQ}$ & $704^{\circ} \mathrm{C} / 24 \mathrm{hr} . / \mathrm{AC}$ & $871^{\circ} \mathrm{C} / 32 \mathrm{hr} . / \mathrm{AC}$ \\
\hline PWA 1484 & HT3 & $1325^{\circ} \mathrm{C} / 1 \mathrm{hr} . \rightarrow 1332^{\circ} \mathrm{C} / 1 \mathrm{hr} . \rightarrow 1338^{\circ} \mathrm{C} / 10 \mathrm{hr} . / \mathrm{GFQ}$ & $1080^{\circ} \mathrm{C} / 4 \mathrm{hr} . / \mathrm{GFQ}$ & $704^{\circ} \mathrm{C} / 24 \mathrm{hr} . / \mathrm{AC}$ & $871^{\circ} \mathrm{C} / 32 \mathrm{hr} . / \mathrm{AC}$ \\
\hline
\end{tabular}

*All samples were heated from room temperature to $1200^{\circ} \mathrm{C}$ for $0.5 \mathrm{hr}$. at a rate of $20^{\circ} \mathrm{C} /$ minute, then samples were heated to the first soak temperature at a rate of $10^{\circ} \mathrm{C} /$ minute. All ramping following the first soak temperature is at a rate of $1^{\circ} \mathrm{C} /$ minute. GFQ is Gas Furnace Quench (ultra high purity $\mathrm{He}$ ) and AC is Air Cool. Solution and Coating heat treatments were performed under vacuum and Age heat treatments were performed in air environments. 


\section{Mechanical Behavior}

After heat treatment, creep and tensile specimens were machined from the single crystal bars using a low stress grind technique by Joliet Metallurgical (Joliet, IL). All specimens had a gage diameter of $45 \mathrm{~mm}$ and a gage length of $260 \mathrm{~mm}$. Constant load creep testing was performed with the following conditions: $704^{\circ} \mathrm{C} / 862 \mathrm{MPa}, \quad 704^{\circ} \mathrm{C} / 758 \mathrm{MPa}, 760^{\circ} \mathrm{C} / 690 \mathrm{MPa}$, and $815^{\circ} \mathrm{C} / 621 \mathrm{MPa}$. Creep tests were run either to failure for lifetime determination or were interrupted after $0.5 \%$ secondary creep for TEM observation. Tensile testing was performed on samples of the same geometry that was used for creep testing. Tensile tests were performed at $700^{\circ} \mathrm{C}$ and $815^{\circ} \mathrm{C}$ with a constant strain rate of $2.54 \min ^{-1}\left(0.042 \mathrm{~s}^{-1}\right)$.

\section{$\underline{\text { X-Ray Diffraction }}$}

X-ray diffraction experiments were performed on disks cut from the single crystal bars following the coating heat treatment cycle. The disks were separated into four groups and three were heated again to $1080^{\circ} \mathrm{C}$ for either $6 \mathrm{hr}$., $96 \mathrm{hr}$., or $996 \mathrm{hr}$. This resulted in samples aged for $4,10,100$, and 1000 hours at $1080^{\circ} \mathrm{C}$. These over aged samples were used to show the trend in the evolution of lattice misfit for all three alloys. Each disk was thinned and polished to a final thickness of $0.7 \mathrm{~mm}$. Full scans $\left(0.02^{\circ}\right.$ scan step, $1 \mathrm{~s}$ dwell time, $10^{\circ}$ to $\left.130^{\circ}\right)$ and slow scans of the $(002)$ reflections $\left(0.01^{\circ}\right.$ scan step, $3-5 \mathrm{~s}$ dwell time $)$ were obtained using a Rigaku $\theta / 2 \theta$ X-ray diffractometer at the Advanced Materials Processing and Analysis Center (AMPAC) at the University of Central Florida. Peak deconvolution was performed with the MDI Jade software package (ver. 7) on the accompanying workstation to separate the contributions of the $\gamma$ and $\gamma^{\prime}$ phases while accounting for both $\mathrm{k}_{\alpha 1}$ and $\mathrm{k}_{\alpha 2}$ wavelengths. Lattice parameters were determined utilizing the calculated positions of the $k_{\alpha 11}$ peak of both phases and the lattice misfit was determined by Equation 1.

$$
\delta=\frac{2\left(a^{\gamma^{\prime}}-a^{\gamma}\right)}{\left(a^{\gamma^{\prime}}+a^{\gamma}\right)}
$$

\section{$\underline{\text { TEM Observation }}$}

Foils were prepared from the interrupted creep specimens perpendicular to the [001] growth direction. The foils were thinned to around $100 \mu \mathrm{m}$ thick and $3 \mathrm{~mm}$ diameter disks were prepared with a punch. TEM foils were further thinned using a polishing die to a final thickness between 30 and $70 \mu \mathrm{m}$. They were then electropolished at 20 volts with a polishing solution of $10 \%$ perchloric acid, and $90 \%$ methanol at a temperature of $25^{\circ} \mathrm{C}$. The electrolyte was cooled by the addition of liquid nitrogen. TEM samples were observed at $200 \mathrm{keV}$ on a Jeol 200CX microscope at the Major Analytical Instrumentation Center at the University of Florida.

\section{Results}

\section{Microstructure}

All three alloys are traditional nickel-base superalloys with a two phase $\gamma / \gamma^{\prime}$ microstructure. The gamma prime precipitates formed as both primary precipitates (cuboidal with average edge length $\sim 0.3-0.5 \mu \mathrm{m}$ ) and secondary precipitates (spherical with average diameter $\sim 10-50 \mathrm{~nm}$ ). Examples of both forms of $\gamma^{\prime}$ can be seen

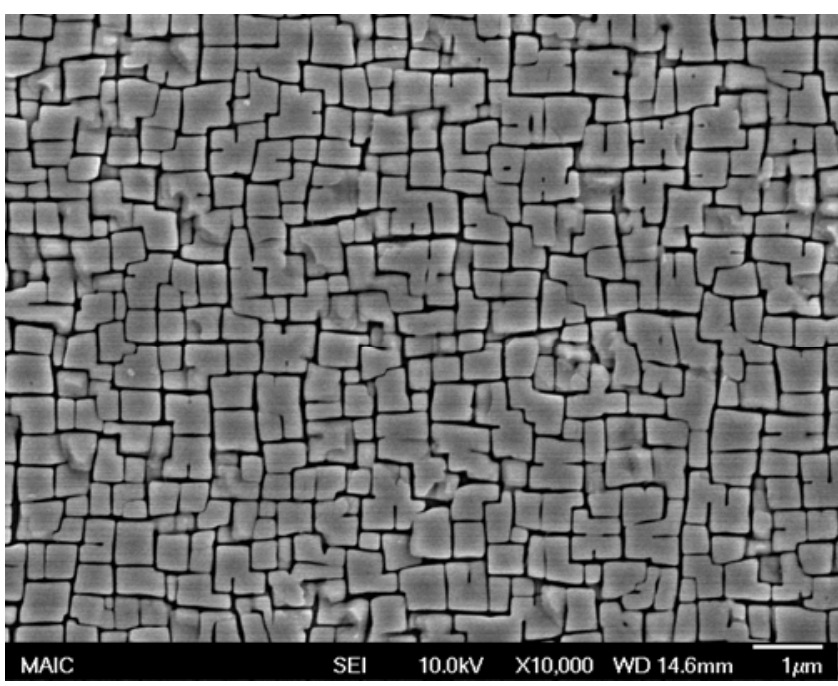

Figure I. Primary $\gamma^{\prime}$ precipitates in PWA 1484 (electrolytic etch)

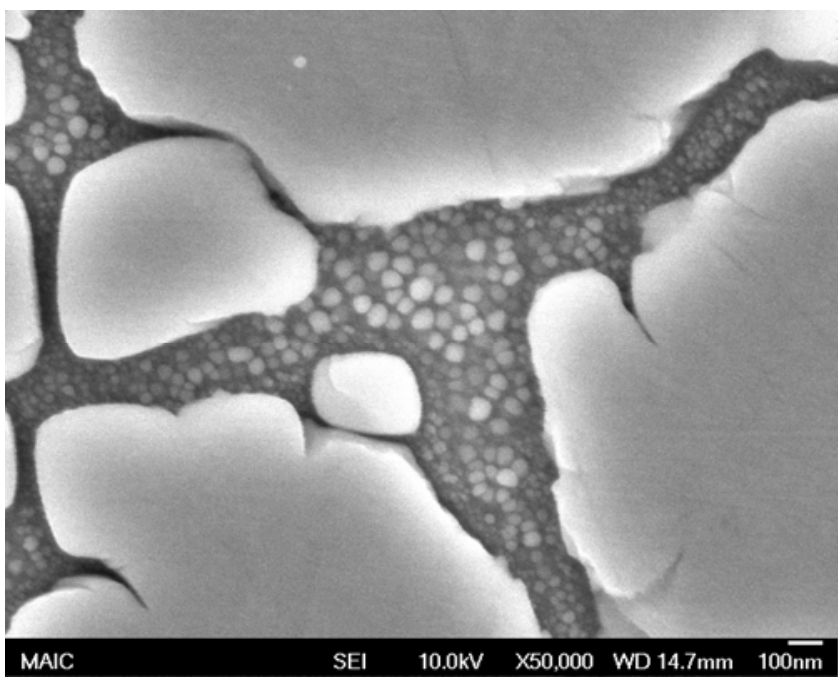

Figure II. Secondary $\gamma^{\prime}$ precipitates in PWA 1480 (electrolytic etch).

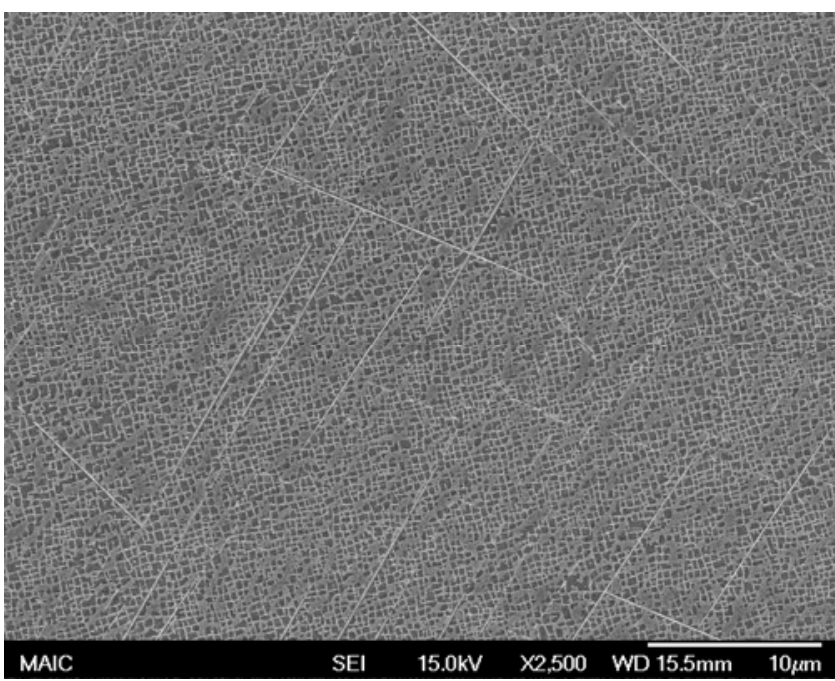

Figure III. TCP phases in PWA 1480+ following an interrupted creep test (HT age, $815^{\circ} \mathrm{C}, 621 \mathrm{MPa}, 0.74 \%$ creep, 225 hours). 
in Figures I and II. In addition to $\gamma$ and $\gamma$, carbides are also present in a low volume fraction in all three alloys. PWA 1484 contained the least amount of carbide phase. PWA 1480+ with its $\mathrm{Re}$ addition contained the most carbide phase, which is likely due to a decreased solubility of $\mathrm{C}$ because of the Re content. The interrupted PWA 1480+ creep specimens also contained prevalent Topologically Close Packed (TCP) phases, Figure III. These phases formed early during creep. The precipitation of TCP phases is likely due to the addition of Re to PWA 1480 without modifying the alloy composition to resist TCP formation.

\section{$\underline{\text { Tensile Behavior }}$}

At both test temperatures, the tensile behaviors of PWA 1480 and PWA $1480+$ are very similar. An example stress-strain curve $\left(700^{\circ} \mathrm{C}\right)$ is presented in Figure IV. Both alloys exhibit yield points at $815^{\circ} \mathrm{C}$ and display very similar strain hardening behavior after yielding. For three of the four conditions, PWA 1480+ has a greater yield stress than conventional PWA 1480, which is likely due to the solid solution strengthening effect of the Re addition. For both test temperatures, the HT age appears to decrease ductility in PWA $1480\left(11.6 \%\right.$ to $6.3 \%$ at $700^{\circ} \mathrm{C}$ and $18.3 \%$ to 15.2 at $815^{\circ} \mathrm{C}$ ) while simultaneously reducing the yield stress $\left(1357 \mathrm{MPa}\right.$ to $1333 \mathrm{MPa}$ at $700^{\circ} \mathrm{C}$ and $1281 \mathrm{MPa}$ to $1212 \mathrm{MPa}$ at $815^{\circ} \mathrm{C}$, LT and HT respectively). PWA $1480+$, though, had increased ductility and yield strength in the HT age when compared to the LT age condition. Comparing test temperatures for PWA $1480+$ it can be seen that the ductility is improved at $815^{\circ} \mathrm{C}$ while the strength is not significantly affected, Table III. Additionally, the higher strength PWA 1480+ exhibited less ductility than PWA 1480 in the LT condition but similar ductility in the HT condition. Tensile strength and elongation measurements from all three alloys are presented in Table III. Based on these tensile results, PWA 1480 appears to have a slight dependence on age heat treatment temperature while PWA 1480+ does not.
The tensile behavior of PWA 1484 was somewhat different from PWA 1480 (and PWA 1480+). PWA 1484 was characterized by a significantly lower yield point, greater ductility, and greater amount of plastic work hardening. At $700^{\circ} \mathrm{C}$, the flow stress of PWA 1484 continues to increase until failure. At $815^{\circ} \mathrm{C}$, the flow stress increases to the ultimate tensile strength, UTS, following 24\% plastic deformation. All of the PWA 1484 tests exhibited between 14 and $23 \%$ elongation compared with $5-11 \%$ for PWA 1480 and 2-10\% for PWA 1480+, Table III. For PWA 1480 and PWA 1484, the LT age condition is slightly stronger than the HT age condition. For PWA $1480+$, however, the HT age produces greater yield strength at both test temperatures. Also of note, PWA 1480 is stronger at the lower temperature of $700^{\circ} \mathrm{C}$ than it is

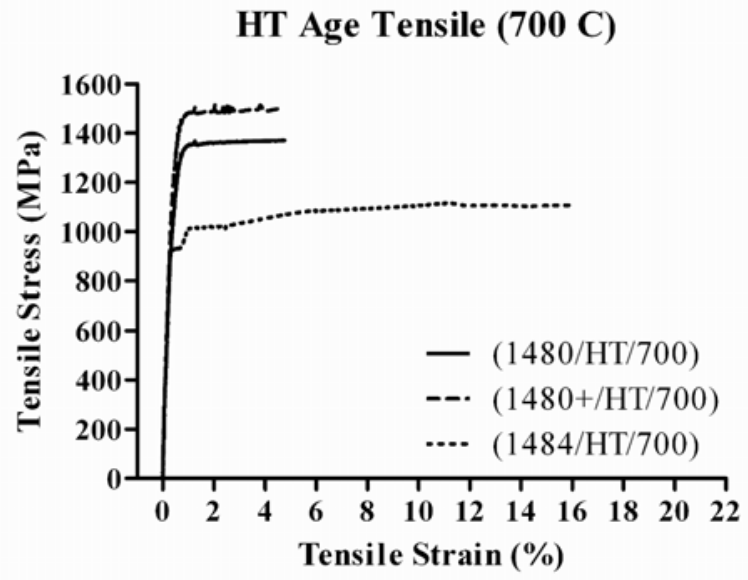

Figure IV. Example stress-strain curve $\left(\mathrm{HT}\right.$ age, $\left.700^{\circ} \mathrm{C}\right)$.

Table III. Tensile results at $700^{\circ} \mathrm{C}$ and $815^{\circ} \mathrm{C}$. Tensile tests were conducted in air at a constant strain rate of $0.042 \mathrm{~s}^{-1}$.

\begin{tabular}{|c|c|c|c|c|c|c|c|}
\hline & Temperature & Age & $\sigma_{\mathrm{y}}(\mathrm{MPa})$ & $\begin{array}{l}\text { UTS (MPa) } \\
\mathrm{y} / \mathrm{p} / \mathrm{f}^{*}\end{array}$ & $\sigma_{\mathrm{f}}(\mathrm{MPa})$ & $\begin{array}{l}\text { Elongation } \\
\text { at Failure (\%) }\end{array}$ & RIA (\%) \\
\hline \multirow{4}{*}{ PWA 1480} & \multirow{2}{*}{$700^{\circ} \mathrm{C}$} & LT & 1357.44 & 1429.33 (f) & 1604.29 & 11.76 & 10.93 \\
\hline & & HT & 1333.45 & $1371.15(\mathrm{p})$ & 1459.98 & 5.49 & 6.09 \\
\hline & \multirow{2}{*}{$815^{\circ} \mathrm{C}$} & LT & 1281.39 & $1287.39(\mathrm{y})$ & 1321.31 & 12.36 & 16.70 \\
\hline & & HT & 1212.24 & $1213.76(y)$ & 1220.33 & 7.68 & 14.09 \\
\hline \multirow{4}{*}{ PWA 1480+ } & \multirow{2}{*}{$700^{\circ} \mathrm{C}$} & LT & 1149.77 & 1215.07 (f) & 1250.34 & 2.58 & 2.81 \\
\hline & & HT & 1375.57 & $1516.20(f)$ & 1606.16 & 5.09 & 6.63 \\
\hline & \multirow{2}{*}{$815^{\circ} \mathrm{C}$} & LT & 1267.39 & $1351.91(\mathrm{y})$ & 1340.15 & 7.12 & 11.46 \\
\hline & & HT & 1378.33 & $1385.63(\mathrm{y})$ & 1384.00 & 8.99 & 15.67 \\
\hline \multirow{4}{*}{ PWA 1484} & \multirow{2}{*}{$700^{\circ} \mathrm{C}$} & LT & 948.72 & 1112.69 (f) & 1314.27 & 13.46 & 15.86 \\
\hline & & HT & 931.76 & $1116.55(\mathrm{p})$ & 1328.08 & 16.58 & 16.72 \\
\hline & \multirow{2}{*}{$815^{\circ} \mathrm{C}$} & LT & 907.90 & $1199.62(p)$ & 1397.51 & 18.22 & 20.71 \\
\hline & & HT & 897.90 & $1141.44(p)$ & 1203.85 & 19.26 & 12.92 \\
\hline
\end{tabular}

*y/p/f: y: UTS at yielding, p: UTS during the plastic stage and not at yielding or fracture, f: UTS at fracture. 
at $815^{\circ} \mathrm{C}$. The opposite is true for PWA 1484. Clearly, PWA 1484 was optimized for better high temperature strength properties which may explain the improvement in strength at the higher temperature [19].

\section{$\underline{\text { Creep Behavior }}$}

As stated earlier, creep testing was conducted at four combinations of temperature and initial stress. After running several tests at $704^{\circ} \mathrm{C} / 758 \mathrm{MPa}$ the initial stress was increased to $862 \mathrm{MPa}$ due to the very long creep lives of PWA 1484, 1700+ hours, at the $758 \mathrm{MPa}$ stress level. PWA 1480 exhibits normal creep behavior at these conditions. Following the start of a creep test, PWA 1480 exhibited a small amount of primary creep (less than $0.5 \%$ ) before transitioning to a low minimum creep rate that increases continually until failure. As a result, PWA 1480 creep curves exhibited only tertiary creep due to the accelerating creep rate.

The second generation alloy PWA 1484, however, displays a brief incubation period followed by a large primary creep strain. Primary creep typically ends very soon after it starts by transitioning to secondary creep with a constant, low creep rate. Most of the rupture life of the PWA 1484 specimens occurs during secondary creep. Plotted as creep elongation (\%) vs. run time (hr.), the secondary creep stage of these alloys is very nearly linear. As the test nears the eventual failure life of the alloy, the creep rate slowly begins to increase. The rising creep rate continues to increase until failure, and thus comprises the tertiary stage of creep for PWA 1484. For the highest temperature test, PWA 1480 has a rupture life that is roughly $10 \%$ of the rupture life of PWA 1484, Table IV. As the temperature is lowered (and the stress increases), the relative difference between the creep lives decreases. At $760^{\circ} \mathrm{C}$, PWA 1480 has increased to a lifetime of about $25 \%$ of PWA 1484 . At $704^{\circ} \mathrm{C}$, however, PWA 1480 has a greater rupture life than PWA 1484. In the LT age condition, for example, the rupture life of PWA 1484 is now only $10 \%$ of the life of PWA 1480, Figures V-VII.

The prominence of the primary creep stage of PWA 1484 is evident for all test conditions used in this investigation. Generally, as the temperature is increased and the load decreased, the magnitude of primary creep decreases. There does not appear to be a significant difference in primary creep between PWA 1480 and PWA $1480+$ as a result of temperature or load, Figures VIIIIX. PWA 1484, however, shows a fairly strong primary creep dependence on age heat treatment. For all PWA 1484 creep tests, the LT aged samples produced significantly more primary creep than the HT aged samples. The effect of test temperature/stress and age heat treatment on PWA 1484 can be readily seen in Figures V-VII, X. Additionally, the ratio of creep load to yield strength appears to not be a significant factor in predicting the onset of secondary creep, Table V. While at each temperature, PWA 1484 had the lowest yield strength (YS) and, as a result, the largest ratios, PWA 1484 at $815^{\circ} \mathrm{C}$ was tested at similar creep stress to yield stress ratios to PWA 1480 and PWA 1480+ at $704^{\circ} \mathrm{C}$. Based on the range of conditions used herein, PWA 1484 produced significantly larger primary creep strains than the other two alloys regardless of creep stress to yield stress ratio.

Post-test measurements revealed that the PWA 1484 samples deformed non-uniformly during creep testing. Inhomogeneous creep has been shown to occur frequently in second generation superalloys like CMSX-4 and PWA 1484 [4, 6, 20]. All of the PWA 1484 samples exhibited a change in the shape of the gage section shape from the original circular cross-section to an elliptical cross-section. The major and minor axes are parallel to $<110>$ directions. Based on reported research, it is believed that the elliptical cross-section is formed mostly during primary creep when limited slip systems are active [4]. Work-hardening should result in greater uniformity of deformation resulting in the initiation of secondary creep. During non-uniform primary creep, the sample cross-section decreases rapidly. As a result, the difference in creep rate between the two age heat treatments of PWA 1484 at $815^{\circ} \mathrm{C} / 621 \mathrm{MPa}$, Figure VII, may be due to changes in cross-sectional area during primary creep. With a smaller cross-section the LT age sample will experience greater applied stress than the HT age and produce greater deformation, giving the impression of a higher creep rate. Contrasting this reasoning are the data produced at $760^{\circ} \mathrm{C} / 690 \mathrm{MPa}$, Figure VI. Here, an even greater difference in primary creep strain yielded nearly identical secondary creep rates between the two age heat treatments. More testing is needed before the cause of the varied secondary creep rate of PWA 1484 (Figure VII) can be stated with confidence.

The addition of $\mathrm{Re}$ to PWA 1480 that improved the tensile properties discussed above also significantly improves the creep behavior of the alloy. The already limited amount of primary creep of PWA 1480 was maintained (or lowered in some cases) in PWA $1480+$ and the creep rate under all heat treatment and test conditions was significantly lower than any other alloy/heat treat combination.

Table IV. Rupture lives and total creep elongation from fulllength creep tests. Also included is time to $1 \%$ and time to $2 \%$ creep. Note: The PWA $1480+$ HT sample at $815^{\circ} \mathrm{C} / 621 \mathrm{MPa}$ failed before $2 \%$ creep was achieved.

\begin{tabular}{|c|c|c|c|c|c|c|}
\hline & Alloy & Age & $\begin{array}{c}\mathrm{t}_{1 \%} \\
\text { (hr.) }\end{array}$ & $\begin{array}{c}\mathrm{t}_{2 \%} \\
\text { (hr.) }\end{array}$ & $\begin{array}{l}\mathrm{t}_{\text {rupture }} \\
\text { (hr.) }\end{array}$ & $\begin{array}{c}\text { Elongation } \\
(\%)\end{array}$ \\
\hline \multirow{6}{*}{ 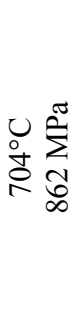 } & \multirow{2}{*}{1480} & LT & 55.2 & 199 & 842 & 16.77 \\
\hline & & HT & 52.0 & 135 & 424 & 14.52 \\
\hline & \multirow{2}{*}{$1480+$} & LT & 63.0 & 427 & 1223 & 5.52 \\
\hline & & HT & 619 & 1225 & 1721 & 3.32 \\
\hline & \multirow{2}{*}{1484} & LT & 7.19 & 8.33 & 90.3 & 38.81 \\
\hline & & HT & 10.1 & 11.7 & 23.7 & 19.64 \\
\hline \multirow{4}{*}{$\begin{array}{l}0 \\
0 \\
0 \\
0\end{array}$} & \multirow{2}{*}{1480} & LT & 56.6 & 117 & 311 & 10.78 \\
\hline & & HT & 47.4 & 124 & 428 & 13.90 \\
\hline & \multirow{2}{*}{1484} & $\mathrm{LT}$ & 3.27 & 4.10 & 1465 & 20.08 \\
\hline & & HT & 5.96 & 13.9 & 1525 & 14.69 \\
\hline \multirow{6}{*}{ 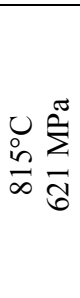 } & \multirow{2}{*}{1480} & $\mathrm{LT}$ & 11.2 & 28.8 & 99.3 & 15.01 \\
\hline & & HT & 14.4 & 26.8 & 77.2 & 14.93 \\
\hline & \multirow{2}{*}{$1480+$} & LT & 486 & 797 & 1239 & 8.94 \\
\hline & & HT & 372 & N/A & 505 & 1.45 \\
\hline & \multirow{2}{*}{1484} & LT & 1.15 & 1.18 & 391 & 13.40 \\
\hline & & HT & 4.92 & 49.8 & 914 & 19.06 \\
\hline
\end{tabular}


Creep (704 C/862 MPa)

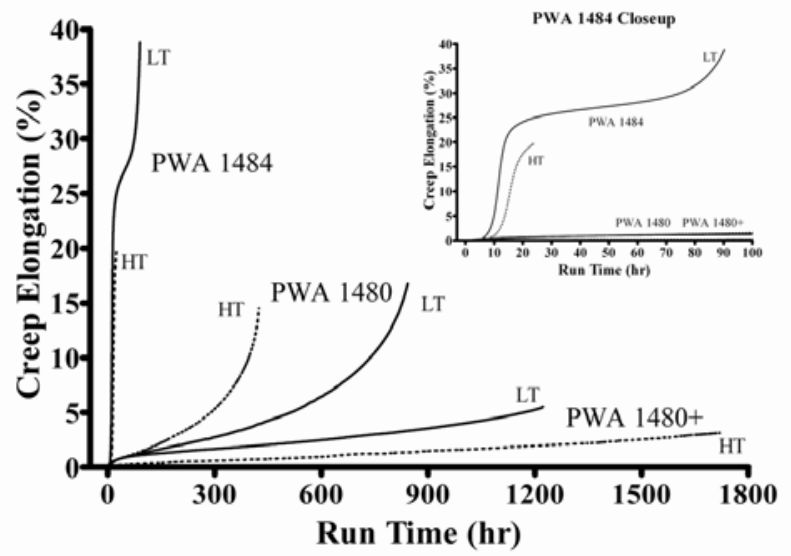

Figure V. Creep at $704^{\circ} \mathrm{C}$ and $862 \mathrm{MPa}$ initial stress.

\section{Creep (760 C/690 MPa)}

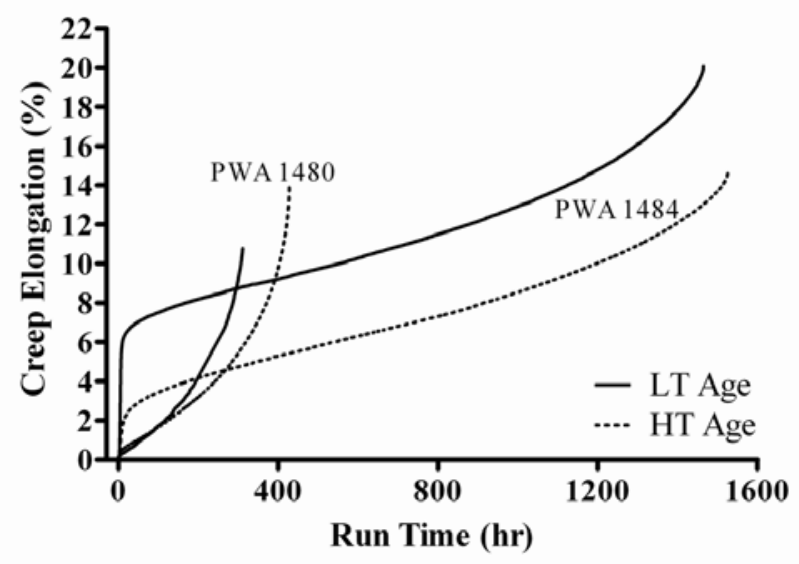

Figure VI. Creep at $760^{\circ} \mathrm{C}$ and $690 \mathrm{MPa}$ initial stress.

\section{Creep (815 C/621 MPa)}

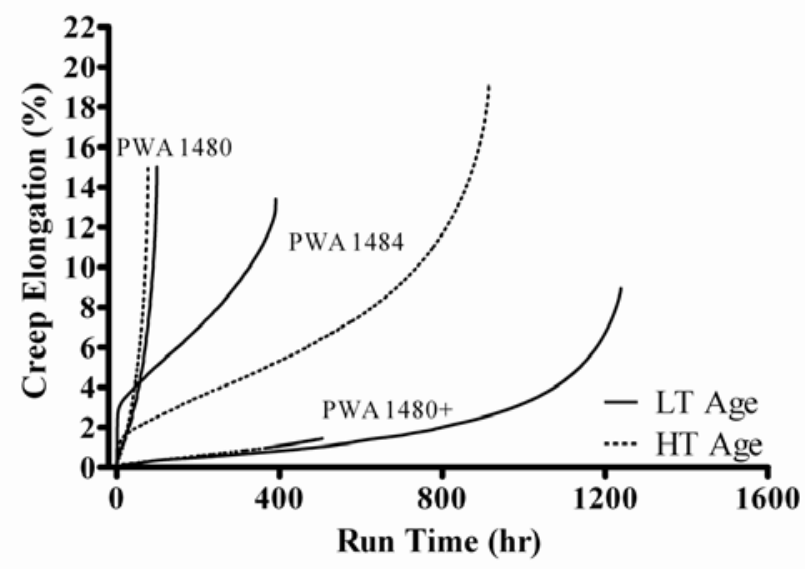

Figure VII. Creep at $815^{\circ} \mathrm{C}$ and $621 \mathrm{MPa}$ initial stress.
Interrupted Creep: PWA 1480

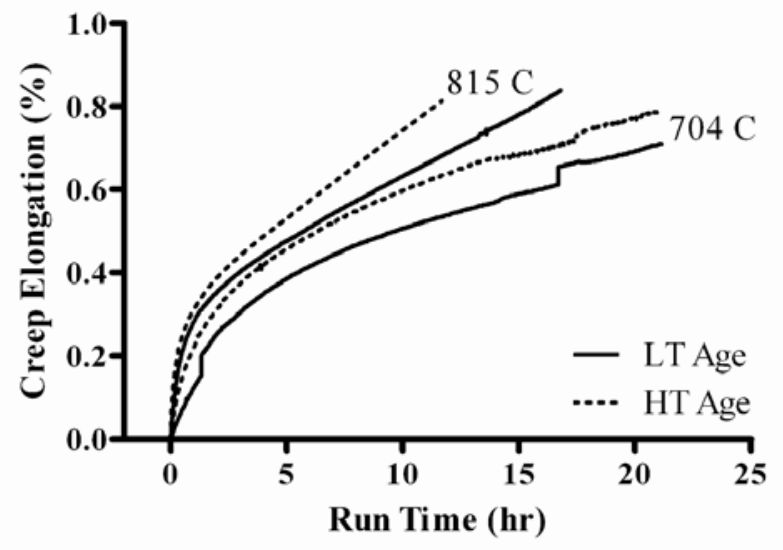

Figure VIII. Primary creep behavior of PWA 1480.

\section{Interrupted Creep: PWA 1480+}

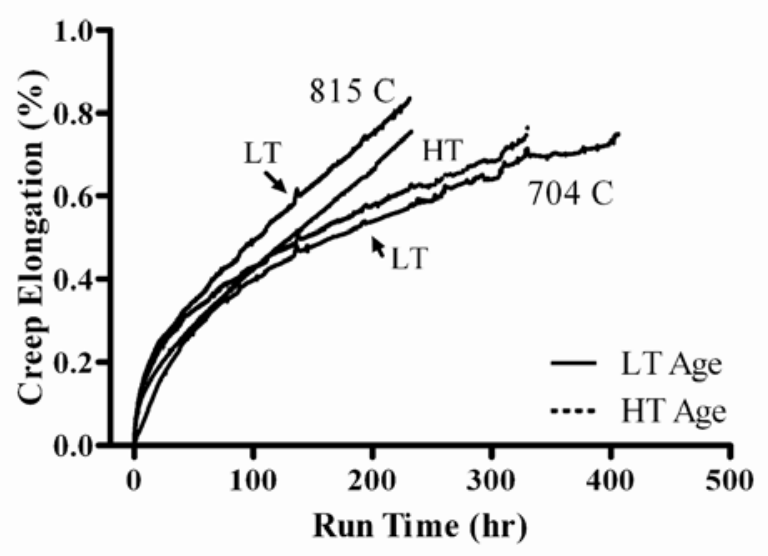

Figure IX. Primary creep behavior of PWA 1480+

\section{Interrupted Creep: PWA 1484}

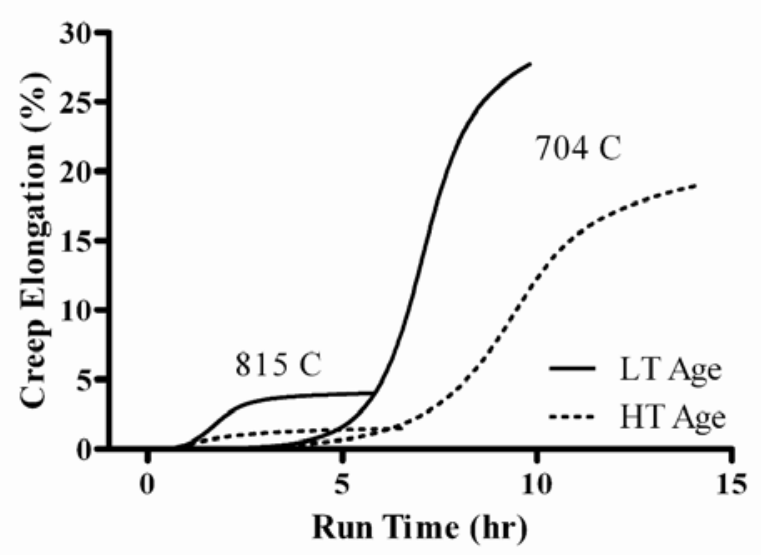

Figure X. Primary creep behavior of PWA 1484. 
Table VI. Primary creep and creep rates from interrupted creep tests.

\begin{tabular}{|c|c|c|c|c|c|c|c|}
\hline \multirow[b]{2}{*}{ Alloy } & \multirow[b]{2}{*}{$\begin{array}{c}\text { Age } \\
\text { HT }\end{array}$} & \multicolumn{3}{|c|}{$704^{\circ} \mathrm{C} / 862 \mathrm{MPa}$} & \multicolumn{3}{|c|}{$815^{\circ} \mathrm{C} / 621 \mathrm{MPa}$} \\
\hline & & $\begin{array}{c}\text { Primary } \\
\text { Creep (\%) }\end{array}$ & $\begin{array}{c}\text { Max. Primary } \\
\text { Creep Rate }(\% / \mathrm{hr} \text {.) }\end{array}$ & $\begin{array}{c}\text { Minimum Creep } \\
\text { Rate }(\% / \mathrm{hr} .)\end{array}$ & $\begin{array}{c}\text { Primary } \\
\text { Creep (\%) }\end{array}$ & $\begin{array}{c}\text { Max. Primary } \\
\text { Creep Rate }(\% / \mathrm{hr} \text {.) }\end{array}$ & $\begin{array}{c}\text { Minimum Creep } \\
\text { Rate }(\% / \mathrm{hr} .)\end{array}$ \\
\hline \multirow{2}{*}{ PWA 1480} & LT & 0.35 & 0.1632 & 0.0116 & 0.34 & 0.6001 & 0.0277 \\
\hline & HT & 0.49 & 0.4015 & 0.0166 & 0.32 & 1.0377 & 0.0418 \\
\hline \multirow{2}{*}{ PWA $1480+$} & $\mathrm{LT}$ & 0.36 & 0.0073 & 0.0007 & 0.22 & 0.0339 & 0.0021 \\
\hline & HT & 0.34 & 0.0296 & 0.0011 & 0.11 & 0.0304 & 0.0022 \\
\hline \multirow{2}{*}{ PWA 1484} & $\mathrm{LT}$ & 24.44 & 10.704 & 1.8697 & 3.68 & 2.4563 & 0.0768 \\
\hline & HT & 16.66 & 4.3877 & 0.7010 & 1.20 & 0.6751 & 0.0454 \\
\hline
\end{tabular}

Table V. Creep loads vs. yield strength for all three alloys.

\begin{tabular}{|c|c|c|c|c|c|}
\hline & & Age & $\begin{array}{c}\sigma_{\mathrm{y}} \\
(\mathrm{MPa})\end{array}$ & $\begin{array}{l}\text { Creep Load } \\
\quad(\mathrm{MPa})\end{array}$ & $\begin{array}{l}\% \\
\sigma_{y}\end{array}$ \\
\hline \multirow{6}{*}{$\begin{array}{l}0 \\
8 \\
8\end{array}$} & \multirow{2}{*}{ PWA 1480} & LT & 1357.44 & 862 & 63.5 \\
\hline & & HT & 1333.45 & 862 & 64.6 \\
\hline & \multirow{2}{*}{ PWA $1480+$} & LT & 1149.77 & 862 & 75.0 \\
\hline & & HT & 1375.57 & 862 & 62.7 \\
\hline & \multirow{2}{*}{ PWA 1484} & $\mathrm{LT}$ & 948.72 & 862 & 90.9 \\
\hline & & HT & 931.76 & 862 & 92.5 \\
\hline \multirow{6}{*}{$\begin{array}{l}\text { in } \\
\frac{\infty}{\infty}\end{array}$} & \multirow{2}{*}{ PWA 1480} & $\mathrm{LT}$ & 1281.39 & 621 & 48.5 \\
\hline & & HT & 1212.24 & 621 & 51.2 \\
\hline & \multirow{2}{*}{ PWA $1480+$} & $\mathrm{LT}$ & 1267.39 & 621 & 49.0 \\
\hline & & HT & 1378.33 & 621 & 45.1 \\
\hline & \multirow{2}{*}{ PWA 1484} & $\mathrm{LT}$ & 907.90 & 621 & 68.4 \\
\hline & & HT & 897.90 & 621 & 69.2 \\
\hline
\end{tabular}

The rupture lifetime of PWA 1480+ was much longer than either PWA 1480 or PWA 1484. While lifetime, primary creep, and secondary creep rate were improved, ductility was significantly reduced for all conditions. Most PWA 1480+ samples failed with less than $5 \%$ creep elongation. The interrupted creep tests of PWA 1480 were stopped around $0.75 \%$ creep elongation for TEM analysis. These tests were terminated following 10 to 25 hours of testing, Figure VIII. The PWA 1480+ samples were terminated following 250 to 450 hours for the same elongation, Figure IX. PWA 1484, though, were terminated following 5 to 15 hours and as much as $28 \%$ creep, Figure $\mathrm{X}$.

TEM analysis of the three alloys following the interrupted creep tests gives insight into the differences in the active deformation mechanisms. PWA 1480, for example, deformed primarily by dislocations confined to the $\gamma$ matrix, Figure XI. The $\gamma / \gamma$, interfaces are lined with matrix dislocations forming large networks along the interfaces. Interfacial dislocations can be seen to have formed in all three alloys, indicative of the onset of secondary creep (and in agreement with mechanical testing data). These results indicate that primary creep of PWA 1480 is completed without the formation of stacking faults and,

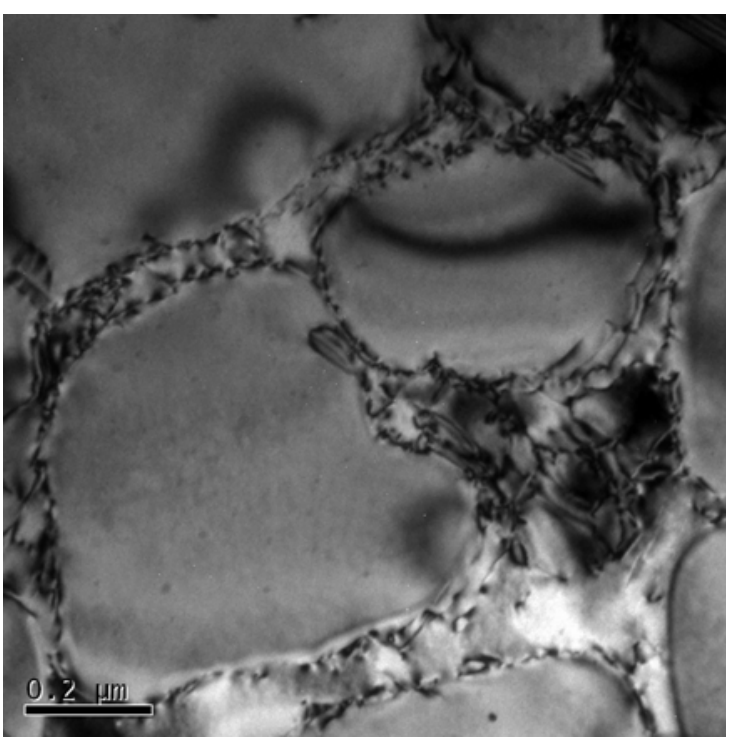

Figure XI. Brightfield TEM micrograph of PWA 1480.

Deformation was primarily limited to the $\gamma$ matrix. Stacking faults in the $\gamma$ ' phase were rare.

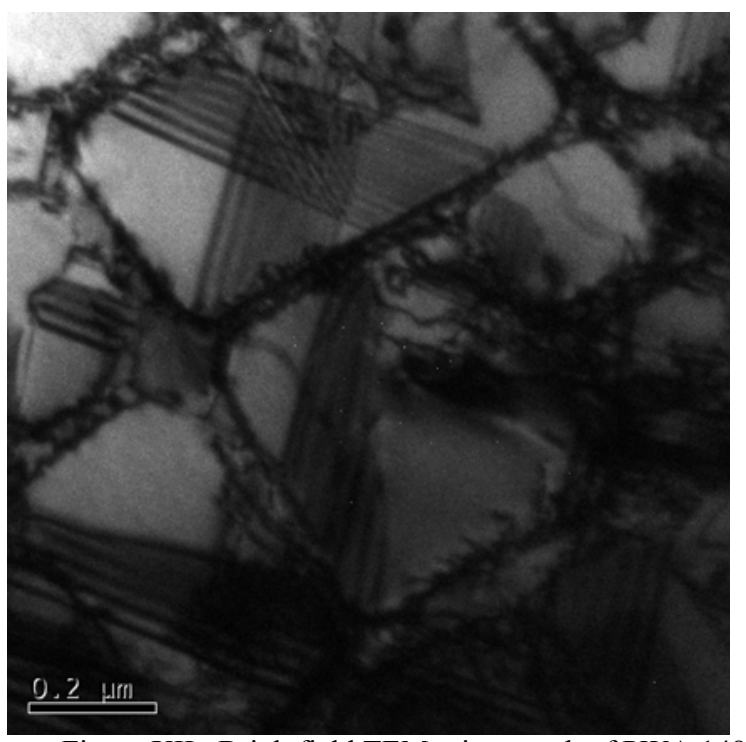

Figure XII. Brightfield TEM micrograph of PWA 1480+. Stacking faults were present in PWA 1480+ acting on at least two different slip planes. 


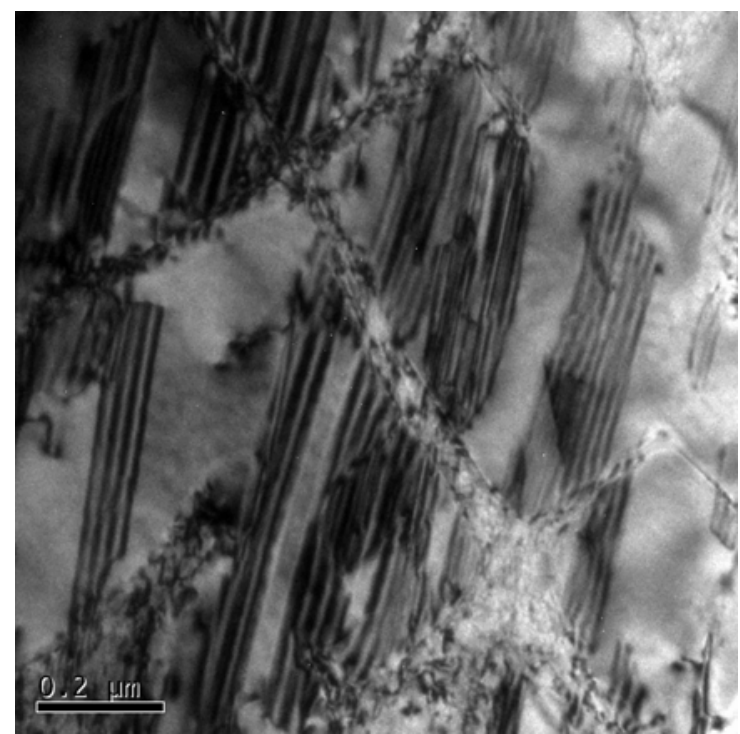

Figure XIII. Brightfield TEM micrograph of PWA 1484.

Stacking fault formation was widespread in the $\gamma^{\prime}$ with several faults in each precipitate.

consequently, $\gamma^{\prime}$ shear is not a dominant deformation mechanism $[3,9,21]$. Stacking faults in PWA 1480 were rarely observed. When the stacking faults were observed, the faults were limited to small regions in the $\gamma^{\prime}$ and rarely do they extend beyond 1 or 2 precipitates. Adding Re to PWA 1480, however, produced a significant increase in stacking fault creation within the $\gamma$, Figure XII. In PWA 1480+, stacking faults were larger and more common than in PWA 1480 without rhenium. They also acted on at least two different slip planes similar to those reported in ruptured specimens in (Link and Feller-Kniepmeier, 1992) [9]. In PWA 1480+, however, these stacking fault "locks" were created in PWA 1480+ soon after primary creep and well before failure. Additionally, PWA 1480+ has the greatest yield strength of the three alloys resulting in the lowest creep stress/yield strength ratio of the three groups.

While the stacking faults (SF) of PWA $1480+$ are greater in number than PWA 1480, they are not present to the same degree as PWA 1484. Stacking faults in PWA 1484 were widespread and stretched across multiple $\gamma^{\prime}$ precipitates, Figure XIII. The stacking faults were commonly arranged in long, sequential rows all traveling along the same slip plane. This contrasts greatly with PWA 1480 (few SF) and PWA 1480+ (SF interacting from more than one slip plane). This arrangement of stacking faults has been commonly linked to large primary creep strains in second generation single crystal, nickel base superalloys [1, 2, 9].

\section{$\underline{\text { X-Ray Diffraction }}$}

X-ray diffraction studies utilized peak deconvolution to obtain the lattice misfit data for the (002) plane as provided in Table VII. Following the $4 \mathrm{hr} .1080^{\circ} \mathrm{C}$ coating heat treatment, the alloy with the smallest magnitude of lattice misfit was PWA 1480+ $(+0.034 \%)$, while the alloy with the largest was PWA 1484 (0.228 ). After 10 hours at $1080^{\circ} \mathrm{C}$, PWA 1484 maintained a large, negative misfit while PWA $1480+$ transitioned from a positive to a negative misfit. PWA 1480, however, produced a misfit value near zero after the 10 hour heat treatment. After 1000 hours, PWA 1480 returned to a negative value nearly double the original
(4 hour HT) misfit value. PWA 1484, decreased slightly to $0.201 \%$. The modified alloy, PWA $1480+$ exhibited a near zero misfit value of $+0.019 \%$.

Overall, PWA 1480 and PWA 1480+ displayed very similar misfit trends with only about $0.05 \%$ misfit difference between the two with 10 hour or more of heat treatment. The samples with the 4 hour heat treatment displayed the greatest disparity as a result of differences in coherency/microstructure following the solution heat treatment. As the high temperature age continues, $\gamma$ ' coarsening takes place and the initial differences between the two alloys are reduced. The difference in misfit for PWA 1480 and PWA $1480+$ begins at $0.04 \%$ and it becomes $0.05 \%$ after 10 hours and $0.02 \%$ after 1000 hours. PWA 1484 , however, maintains a larger, negative misfit throughout all three heat treatments. The larger misfit of PWA 1484 would suggest a decrease in primary creep due to the alloy's enhanced ability to form interfacial networks that might prevent $\gamma$ ' shear. As already shown through mechanical testing, however, this is not the case. The decrease in misfit from 10 hours to 1000 hours for PWA 1484 is about $0.05 \%$.

Table VII. Lattice misfit (\%) following a $1080^{\circ} \mathrm{C}$ heat treatment.

\begin{tabular}{|lccc|}
\hline & \multicolumn{3}{c|}{ Heat treatment time at $1080 \mathrm{C}$} \\
& $4 \mathrm{hr}$. & $10 \mathrm{hr}$. & $1000 \mathrm{hr}$. \\
\hline PWA 1480 & -0.075 & +0.002 & -0.138 \\
PWA 1480+ & +0.034 & -0.052 & +0.019 \\
PWA 1484 & -0.228 & -0.251 & -0.201 \\
\hline
\end{tabular}

\section{Discussion}

The primary creep behavior of single crystal nickel-base superalloys has proven to be a problem involving many factors. Previous research has shown a dependence of primary creep on orientation, magnitude of the load applied, secondary $\gamma^{\prime}$ precipitates, and possibly rhenium and/or ruthenium content, all of which may lead to non-uniform deformation (only 1 or 2 slip systems) and stacking fault shear (of the $\gamma^{\prime}$ phase) [2-4, 7]. The current investigation focuses on the effect of composition and heat treatment on primary creep of PWA 1480 and PWA 1484. By adding 3wt.\% Re to PWA 1480 an experimental second generation alloy was produced to investigate the effect of rhenium. The first generation PWA 1480 was shown to have a greater yield strength than PWA 1484, but less ductility and toughness. This is possibly due to the increased $\gamma^{\prime}$ strengthening of PWA 1480 achieved by the addition of Ta and Ti. The addition of Re significantly improved the yield strength of PWA 1480 but did not alter the plastic deformation behavior with the exception of reduced ductility.

Comparing yield strength to the applied initial creep stress, Table $\mathrm{V}$, it is apparent that the large primary creep strains in PWA 1484 at $704^{\circ} \mathrm{C}$ were produced at greater than $90 \%$ of the yield strength. As the primary creep stage continues, the cross-sectional area decreases significantly leading to the possibility that the actual stress level during creep at $704^{\circ} \mathrm{C} / 862 \mathrm{MPa}$ for PWA 1484 may eventually exceed the yield stress. This high load produced primary creep strains of $17 \%$ for the LT age and $24 \%$ for the HT age. Such a high stress level, however, is not necessary to produce large primary creep strains in PWA 1484 . At $704^{\circ} \mathrm{C}$ and a reduced load of $758 \mathrm{MPa}$, primary creep strains of $5 \%$ for the LT age and $10-14 \%$ for the HT age are possible. This clearly 
indicates that the magnitude of the applied initial stress contribute to the amount of primary creep that results as reported by (Rae and Reed, 2007) [2] and (Shah et al., 2004) [4]. The stress ratio for creep testing at $815^{\circ} \mathrm{C}$ of PWA 1484 is similar to the ratios for PWA 1480 and PWA $1480+$ at $704^{\circ} \mathrm{C}$. Even still, the primary creep of PWA 1484 is significantly larger than the other two alloys leading to the conclusion that the ratio of creep stress to yield stress is not the cause of primary creep though it may influence the amount of strain produced.

In the narrow sense of comparing rupture lives only, PWA 1484 out-performed PWA 1480 at all but highest load at the lowest temperature $\left(704^{\circ} \mathrm{C} / 862 \mathrm{MPa}\right)$. Simply adding Re to PWA 1480 , however, remarkably improved the rupture life of PWA 1480. Creep ductility and toughness were decreased, but the minimum creep rate was decreased by over an order of magnitude and the same low primary creep behavior was maintained. The time to $1 \%$ creep shows the difference in primary creep behaviors very clearly, Table IV. While the lifetime of PWA 1484 is the longest at several conditions, the time to $1 \%$ creep is the shortest. Continuing the discussion to time from $1 \%$ to $2 \%$ creep strain, it can be seen that PWA 1480 and PWA 1480+ experience a much longer time from 1 to $2 \%$ than from 0 to $1 \%$. For several PWA 1484 samples, however, the time from $1 \%$ to $2 \%$ creep was achieved quicker than the first $1 \%$ of creep strain because the creep rate is still increasing through the first several percent primary creep.

Rhenium additions have been indicated as a potential contributor to primary creep because of the propensity of second and third generation alloys to show this behavior. While it is possible that Re has some sort of contributory effect on primary creep in second generation and later alloys, the present investigation shows an improvement in creep properties and a slight decrease in primary creep when Re is added to PWA 1480. The difference between PWA 1480 and PWA 1484, however, is more than just the addition of rhenium. PWA 1484 has increased solid solution strengtheners/refractory content and decreased $\gamma$ ' hardeners. Based on the present investigation, Re alone does not appear to cause increased primary creep. Additionally, the shear of $\gamma^{\prime}$ precipitates which is the hallmark of this primary creep behavior may be affected by the relative strengthening of the $\gamma$ phase and weakening of the $\gamma^{\prime}$ phase. As dislocation shear of the $\gamma$ phase becomes more difficult and stacking fault shear of the $\gamma^{\prime}$ phase easier, shear band formation would be expected. Composition is an important factor to consider, but not simply limited to a discussion of Re content.

With shear band formation the likely mechanism for large primary creep strains, an understanding of the $\gamma / \gamma^{\prime}$ interface is appropriate. Upon cooling from the solution heat treatment the $\gamma$ ' precipitates are mostly coherent. During the ensuing aging heat treatments, the precipitates coarsen slightly to achieve optimal strength and dislocations begin forming along the interfaces if the lattice mismatch is large enough. Additionally, the cooling rate that is used following aging may or may not result in secondary $\gamma$ ' precipitates in the $\gamma$ matrix channels. The result is a complex mix of $\gamma^{\prime}$ sizes and shapes and varied amounts of interfacial dislocations depending on the procedures used to prepare the alloys for service. Secondary $\gamma^{\prime}$ was shown to be present in all three alloys following both age heat treatments with no differences in primary creep in PWA 1480 and PWA 1480+.
Significant changes in primary creep of PWA 1484, however, were created with no change in the secondary $\gamma^{\prime}$ population. In order to better characterize the effect of age heat treatments on the $\gamma / \gamma$ " microstructures, future work will focus on lattice misfit measurements of the alloys with both aging heat treatments at the heat treatment temperatures.

When dislocations are confined to the $\gamma$ matrix primary creep is low due to the interaction of dislocations within the narrow spaces of the $\gamma$ channels. During $\gamma^{\prime}$ shear dislocations can move longer distances without interacting with an obstacle in the $\gamma^{\prime}$ precipitates resulting in large creep strains and few dislocation interactions [2]. The HT age heat treatment helps to verify this idea. The longer time and higher temperature of the HT age allows the $\gamma^{\prime}$ to coarsen, decreasing coherency. The greater incoherency of the $\gamma^{\prime}$ precipitates after the HT age may be responsible for the decrease in primary creep at all test conditions for PWA 1484 while no significant change in primary creep can be found in PWA 1480 and PWA 1480+. Increasing incoherency in PWA 1484 following heat treatment may reduce the ability of dislocations to enter the $\gamma$ ' phase to form stacking faults. PWA 1480 shows little effect with heat treatment because the formation of stacking faults is already difficult. Another potential benefit of the HT age may be due to widening of the $\gamma$ matrix channels. As the channels are widened, shear of the matrix would be promoted while shear would be reduced due to a lower orowan stress increment. This effect has recently been explored for CMSX-4 through the use of constitutive modeling [22]. While there was shown to be a large improvement in creep lifetime by increasing the $\gamma$ channel width, this effect was small during primary creep. In fact, at intermediate temperatures and high loads the amount of primary creep produced for three different channel widths produced similar primary creep strains. As a result of these considerations, the benefit of the HT age appears to primarily be linked to coherency and coarsening.

\section{Conclusions}

1. Primary creep behavior is likely controlled by alloy composition as a result of changes to refractory solid solution strengtheners and $\gamma$ ' hardeners. Rhenium additions may play a part in the primary creep behavior of second generation and later alloys, but are not capable of producing large primary creep strains alone.

2. Applying a high temperature age heat treatment can significantly reduce the primary creep attained in PWA 1484. This is likely due to greater incoherency of $\gamma$ ' precipitates within the $\gamma$ matrix.

3. Addition of $3 \mathrm{wt} \% \mathrm{Re}$ to PWA 1480 reduced the minimum creep rate by over an order of magnitude for all creep conditions used and increased the rupture lifetime and yield strength. Ductility, however, was reduced as was the microstructural stability with regard to TCP phase formation resistance.

4. The ability of PWA 1484 to experience large primary creep strains is attributed to limited activation of slip systems and delayed onset of secondary creep. The inability of PWA 1480 to produce large primary creep strains likely results from dislocations confined to the $\gamma$ matrix. PWA $1480+$ displayed stacking fault behavior 
on multiple slip planes resulting in stacking fault interactions that aid in ending primary creep.

\section{Acknowledgments}

The authors wish to acknowledge the Major Analytical Instrumentation Center (MAIC) at the University of Florida (Gainesville, FL) and the Advanced Materials Processing and Analysis Center (AMPAC) at the University of Central Florida (Orlando, FL) for their help in the characterization and analysis of these alloys. The authors also wish to thank Samuel Krotzer, Alan Cetel, and Dilip Shah of Pratt \& Whitney Aircraft Engines for supplying the materials used in this investigation.

\section{References}

1. Rae, C.M.F., N. Matan, and R.C. Reed. The role of stacking fault shear in the primary creep of [001]oriented single crystal superalloys at $750[\mathrm{deg}] \mathrm{C}$ and 750 $\mathrm{MPa}$. in Materials Science and Engineering A, City: Publisher. 2001, 300(1-2): p. 125-134.

2. Rae, C.M.F. and R.C. Reed. Primary Creep in Single Crystal Superalloys: Origins, Mechanisms, and Effects. in Acta Materialia, City: Publisher. 2006, 55: p. 10671081.

3. Sugui, T., et al. Aspects of Primary Creep of a Single Crystal Nickel-Base Superalloy. in Materials Science and Engineering, City: Publisher. 1998, A262: p. 271278.

4. Shah, D.M., et al. Primary Creep in Nickel-Base Superalloys, in Superalloys 2004. Seven Springs, PA: TMS, 2004, p. 197-206.

5. Dilip M. Shah and A. Cetel. Creep Anisotropy in Nickel Base $\gamma, \gamma^{\prime}$ and $\gamma / \gamma^{\prime}$ Superalloy Single Crystals, in Superalloys 1996. Seven Springs, PA: TMS, 1996, p. 273-282.

6. Chen, Q.Z. and D.M. Knowles. Mechanism of $<112>/ 3$ slip initiation and anisotropy of $\gamma^{\prime}$ phase in CMSX-4 during creep at $750 \mathrm{C}$ and $750 \mathrm{MPa}$. in Materials Science and Engineering A, City: Publisher. 2003, 356(1-2): p. 352-367.

7. Kakehi, K. Effect of primary and secondary precipitates on creep strength of Ni-base superalloy single crystals. in Materials Science and Engineering A, City: Publisher. 1999, 278(1-2): p. 135-141.

8. $\quad$ Lin Dongliang, Yao Deliang, and S. Chuanqi. The Effect of Stress and Temperature on the Extent of Primary Creep in Directionally Solidified Nickel-Base Superalloys, in Superalloys 1984. Seven Springs, PA: TMS, 1984, p. 199-210.

9. Link, T. and M. Feller-Kniepmeier. Shear mechanisms of the $\gamma^{\prime}$ phase in single-crystal superalloys and their relation to creep. in Metallurgical and Materials Transactions A, City: Publisher. 1992, 23(1): p. 99-105.
10. Caron, P., et al. Creep deformation anisotorpy in single crystal superalloys, in Superalloys 1988. Seven Springs, PA: TMS, 1988, p. 215-224.

11. Knowles, D.M. and Q.Z. Chen. Superlattice stacking fault formation and twinning during creep in [gamma]/[gamma]' single crystal superalloy CMSX-4 in Materials Science and Engineering A, City: Publisher. 2003, 340(1-2): p. 88-102.

12. Harada, H. Design of Ni-base Superalloys, in Materials Design Approaches and Experiences: TMS, 2001, p. 29 39.

13. Zhang, J.X., et al. The effect of lattice misfit on the dislocation motion in superalloys during hightemperature low-stress creep. in Acta Materialia, City: Publisher. 2005, 53(2005): p. 4623-4633.

14. Link, T., et al. Increase of misfit during creep of superalloys and its correlation with deformation. in Acta Materialia, City: Publisher. 2000, 48(2000): p. 19811994.

15. Bruckner, U., et al. The influence of the dendritic structure on the $\gamma / \gamma^{\prime}$-lattice misfit in the single-crystal nickel-base superalloy CMSX-4. in Materials Science and Engineering, City: Publisher. 1998, A247: p. 23-31.

16. Blavette, D., P. Caron, and T. Khan. An atom-probe study of some fine-scale microstructural features in $\mathrm{Ni}$ based single crystal superalloys, in Superalloys 1988. Seven Springs, PA: TMS, 1988, p. 305-314.

17. Giamei, A.F. and D.L. Anton. Rhenium Additions to a Ni-Base Superalloy: Effects on Microstructure. in Metallurgical Transactions A, City: Publisher. 1985, 16A(November 1985): p. 1997-2005.

18. Darolia, R., D.F. Lahrman, and R.D. Field. Formation of topologically close packed phases in nickel base single crystal superalloys, in Superalloys 1988. Seven Springs, PA: TMs, 1988, p. 255-264.

19. Cetel, A.D. and D.N. Duhl. Second-Generation NickelBase Single Crystal Superalloy, in Superalloys 1988: TMS, 1988, p. 235-244.

20. McLean, M., et al. Anisotropy of high temperature deformation of single crystal superalloys: constitutive laws, modelling, and validation, in Superalloys 1992. Seven Springs, PA: TMS, 1992, p. 609-618.

21. Sugui, T., et al. Formation and Role of Dislocation Networks During High Temperature Creep of a Single Crystal Nickel-Base Superalloy. in Materials Science and Engineering, City: Publisher. 1999, A279: p. 160165 .

22. Ma, A., D. Dye, and R.C. Reed. A model for the creep deformation behaviour of single-crystal superalloy CMSX-4. in Acta Materialia, City: Publisher. 2008, 56(8): p. 1657-1670. 